\title{
Solar Power Generation System for the Canadian Space Agency STRATOS Program
}

\author{
Amine Doulfikar ${ }^{1,}$, Ian Cabales ${ }^{I}$, Akash Hossan $^{l}$, Jeff Bloemink ${ }^{l}$, and Pooya Taheri ${ }^{l}$ \\ ${ }^{1}$ British Columbia Institute of Technology, ECET Department, Burnaby BC, V5G 3H2, Canada
}

\begin{abstract}
This paper discusses the design and application of solar photovoltaics (PV) under aerospace conditions. The application of solar PV that is addressed is the Power Distribution Unit (PDU) for the Canadian Space Agency's (CSA) stratospheric balloon (STRATOS) program. The PDU utilizes four $1 \mathrm{kWh}$ Battery Unit (BUs) that have been sized with volume and weight restrictions in mind. Without the capacity to provide enough energy to support multi-day missions, they are thus supplemented by the solar power generation subsystem presented in this paper. The power generation sub-system includes a bespoke solar panel design and a centralized Maximum Power Point Tracking (MPPT) power conversion unit to maximize the power output of solar panels. The centralized unit can accommodate up to eight solar panels, each consisting of nine individual C60 SunPower solar cells. The centralized MPPT unit consists of two MPPT controllers, each controller supporting up to four solar panels. The MPPT unit is modular and can be easily integrated to the CSA's existing intelligent Battery Management System (BMS).
\end{abstract}

Keywords: MPPT Controller, Solar Power Generation, STRATOS, Canadian Space Agency, Stratospheric Balloon, Aerospace

\section{Introduction}

One common design aspect that engineers are required to tackle for aerospace missions is providing a reliable, continuous source of power to keep scientific instruments operating and collecting data. Solar energy is commonly used as a primary source of energy for missions close to a radiation source, and when going deeper into outer space other devices such as nuclear reactors or Radioisotope Thermoelectric Generators (RTG) are employed. This paper is concerned with the former and its application to the Canadian Space Agency's (CSA) stratospheric balloon program (STRATOS).

These stratospheric balloons allow the CSA to test new technologies, conduct science experiments, and take measurements at altitudes ranging from 18 to $39 \mathrm{~km}$ above sea level. STRATOS provides Canadian academia and industry with an opportunity to test and validate new technologies and perform scientific experiments in a near-space environment at a reduced cost [1]. A challenge they face to support varying mission requirements is the development of a modular power generation and distribution subsystem that can support the 
required scientific payload and auxiliary loads required for the mission. The power generation system must have the capability to provide power to all the loads and last for up to six days. If just consisting of batteries without an independent external source of energy, the battery volume and mass would be impractical. In this project, we designed a candidate solar power generation subsystem for the STRATOS program.

As in other aerospace applications, the most readily available source of energy in the stratosphere is the sun, which can be harnessed using solar photovoltaics (PV). Solar PV panels are non-linear energy sources with an output power that changes depending on the irradiance and ambient temperature. The efficiency of solar cells is low, and it can further decrease based on energy conversion efficiency, temperature, and especially the electrical (current/voltage) operating point. The primary purpose of a maximum power point tracking (MPPT) controller is to find the optimal operating point and output the maximum power possible from the solar panels. A secondary consideration is the efficient design of the power conversion hardware itself. This is all a necessary part of realizing an efficient solar power generation system whether for ground or aerospace applications.

In this project, a bespoke solar module and centralized MPPT unit has been designed that can accommodate up to eight solar panels (in a modular fashion) and maximize the power delivered in accordance with physical device limits. In addition, the MPPT unit can charge up to four $1 \mathrm{kWh}$ Battery Unit (BUs). With complete sunlight exposure, at an altitude of 35 $\mathrm{km}$, this solar panel design generates a peak power of $136 \mathrm{~W}$, while at a lower altitude such as $28 \mathrm{~km}$, the panels can generate a peak power of $72 \mathrm{~W}$. The design of the power generation subsystem consists of a solar panel design, and a Perturb and Observe (P\&O) Maximum Power Point Tracking (MPPT) centralized unit. To meet CSA's requirements, we developed our design to be modular, so that (1) it can easily integrate into any existing Battery Management System (BMS), (2) can be used in multiple flights, and (3) can be easily adjusted to the requirements of the mission at hand. Other than the CSA, Canadian academia and industry that are taking advantage of the STRATOS program would also benefit from our design by allowing them to test their scientific experiments for longer durations in the stratosphere.

The purpose of this paper is to report the results of this MPPT subsystem and communicate lessons learned which may be applicable to all applications of solar PVs, including ground-based renewable installations.

\subsection{Background Information}

The project involved consideration of:

i. Solar cell technology and how they operate under conditions like those seen at the target elevation for this weather balloon (30-40 km above sea level).

ii. Understand and investigate applicable MPPT technologies.

These areas of research are related to the application of solar technology and will be used to link to the proposed project requirements defined by the CSA. The following sections give an overview of the related areas while providing preliminary insight into the project direction.

\subsubsection{Solar Cells}

Solar cells convert solar radiation to direct current electricity. They consist of semiconductor materials with different doping characteristics due to the electric field that is formed at the junction as shown in Fig. 1(a) [2]. When photons of light hit the cell, they transfer energy to the charge carriers, and then the electric field at the junction separates the holes from the electrons which allow direct current to flow once the circuit is closed with an external load $[2]$. 
Many factors can affect the efficiency of solar cells that we have to take into consideration for simulating their performance in a stratospheric balloon mission such as the energy conversion efficiency $(\eta)$ and cell temperature [2].

The first factor that can affect a solar cell efficiency is the energy conversion efficiency $(\eta)$. This term is calculated using the ratio of the maximum power point $\left(\mathrm{P}_{\mathrm{m}}\right)$ divided by the input light irradiance $\left(\mathrm{E}\right.$, in $\left.\mathrm{W} / \mathrm{m}^{2}\right)$ under standard test conditions and the surface area of the solar cell $\left(\mathrm{A}_{\mathrm{c}}\right.$ in $\left.\mathrm{m}^{2}\right)[2]$.

$$
\eta=\frac{P_{m}}{E \times A_{c}}
$$

In stratospheric balloon missions, the physical area is limited for the payload due to available space on the gondola and weight limit; therefore, we are not able to simply scale up the area to produce more energy. Another method to improve energy conversion efficiency is by reducing the reflection of incident light [2]. This can be done by applying an antireflection coating or by optical confinements of incident light with textured surfaces. Source [2] explains that the transformation of the wavelength of light can "enhance the spectral sensitivity of a silicon photodiode from the deep UV and through most of the visible region".

Cell temperature is another factor that affects the efficiency of solar cells. At a given irradiance, solar cells produce a higher voltage as the temperature drops and, conversely, lose voltage in high temperatures [2]. Fig. 1(b) displays the characteristic curve of solar cells under different temperatures. This is an important factor to consider because stratospheric balloons undergo a range of different temperatures as they increase in altitude. Variation of ambient temperature with altitude can be seen graphically in Fig. 1(c).

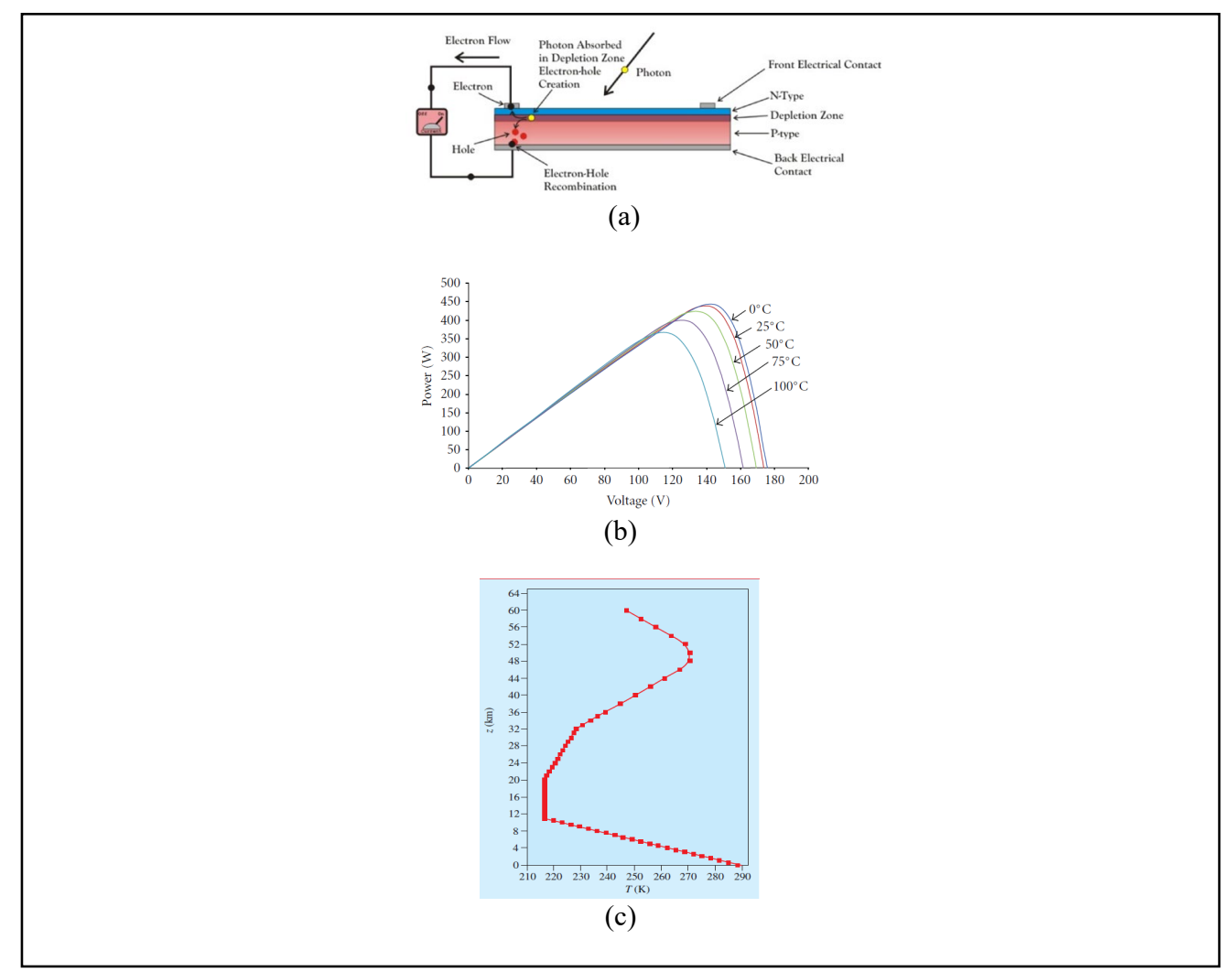

Fig. 1. (a) Solar Cell PN Type [3], (b) The PV characteristic curve of solar cells under different temperature [4], (c) Variation of ambient temperature with altitude [5] 


\subsection{Maximum Power Point Tracking (MPPT) Techniques}

The power output of a solar system varies due to temperature and available solar irradiation on the solar cells [2]. These variables result in a non-linear output with a changing operating point where the power output is at its maximum and the system is most efficient under the current conditions. MPPT algorithms are used to locate this operating point in real-time to maintain and control the ideal solar system output to match the battery requirements and load profile. Advanced MPPT algorithms can resolve voltage mismatches between the solar output and the battery voltage for efficient charging [6].

Many different types of MPPT techniques are available, where each type overcomes specific challenges but in return may have disadvantages. It can be difficult to choose which technique to implement as they vary in complexity, number of sensors required, digital and analogue implementation, convergence speed, tracking ability, and cost-effectiveness [6]. The method we used in this project is the Perturbation and Observation ( $\mathrm{P} \& \mathrm{O}$ ) method due to its simplicity and advantage in conditions where solar irradiance does not change quickly.

\subsubsection{The Perturbation and Observation (P\&O) Algorithm}

As shown in Fig. 2, P\&O algorithm works by increasing or decreasing the array of terminal voltage or current at regular intervals, and then compares the PV output power with that of the previous sample [6]. If the PV output changes and the power increases, the control system will adjust the PV array operating point in that direction. If the power decreases, the operating point will be moved in the opposite direction [6]. The advantage of this method is its simplicity. This method is commonly used when the solar irradiance does not change too quickly, which is likely in this application due to the controlled mission profile and operation above cloud cover. At steady state, the operating point fluctuates lightly around the maximum power point. The disadvantage of this method is poor tracking at low irradiation.

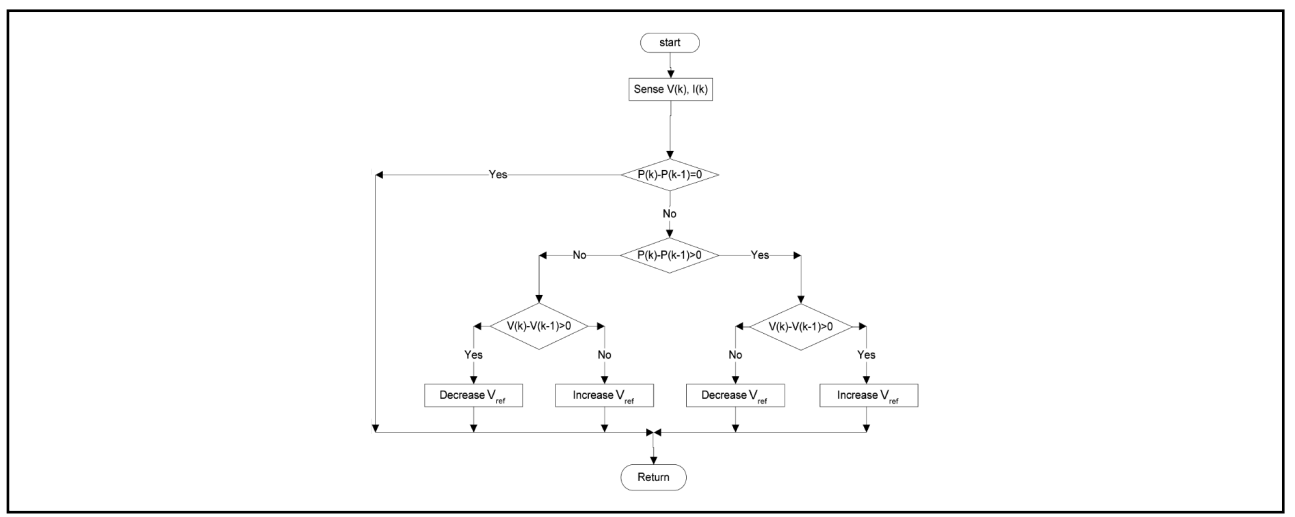

Fig. 2. Flowchart of the $\mathrm{P} \& \mathrm{O}$ algorithm [6]

\section{High-Level Description}

The power flow of the existing STRATOS electrical power system connects a BMS to Battery Units (BUs) and then to a PDU for directing power to individual loads. Our suggested solar charging unit is embedded into the existing power infrastructure with the benefits of modularity. The MPPT unit is the mediator between our array of solar panels and the provided BMS. It allows tracking of the maximum power point of the solar panel IV curve and output the maximum power from the solar panels. It also has the capability to divert 
excess power to a separate MPPT battery unit for strictly powering the MPPT subsystem. The solar panel design consists of nine C60 SunPower solar cells and each group of four panels in direct sunlight can generate $136 \mathrm{~W}$ at an altitude of $35 \mathrm{~km}$ above sea level. The centralized MPPT unit can take up to eight solar panels. There are two MPPT controllers in the centralized unit, in which each controller can take up to four solar panels. The placement of the solar panel are on either side of the CSA Carmencita gondola, where one group of four solar panels will be in sunlight and the other group of four will be in shade. The group that will be in sunlight will be electrically connected to the BUs, while the group in shade, will be automatically electrically disconnected.

The solar panel design consists of five sections: selecting solar cells, developing a 3D model of the solar panel, developing a Blender Model of the solar panels and gondola for Collada file, System Tool Kit (STK) power generation simulation, and modeling the currentvoltage (IV) and power-voltage (PV) curves of the panel design using MATLAB Simulink.

Fig. 3 (a) demonstrates the high-level overview of the project and the CSA pre-existing systems. Fig. 3 (b) demonstrates the high-level structure of the solar panel design and MPPT controller. Four solar panels are connected in series to increase the voltage input of the system. The voltage and current are measured using sensors. The outputs of the sensors are connected to a microcontroller. The solar panel output is connected to a buck converter that will change the operating point (voltage, current) of the panel, and then in turn connected to a boost converter to bring the voltage up to $24 \mathrm{~V}$ in order to charge the CSA BUs. A current sensor is placed in between the boost converter and battery to determine if the batteries are all fully charged or not. The MPPT P\&O algorithm is processed by a microcontroller. Using the voltage and current output, the power of the solar panel can be calculated. The microcontroller will either increase or decrease the buck converter output depending on the measured power until it determines the maximum power the solar panels can output.

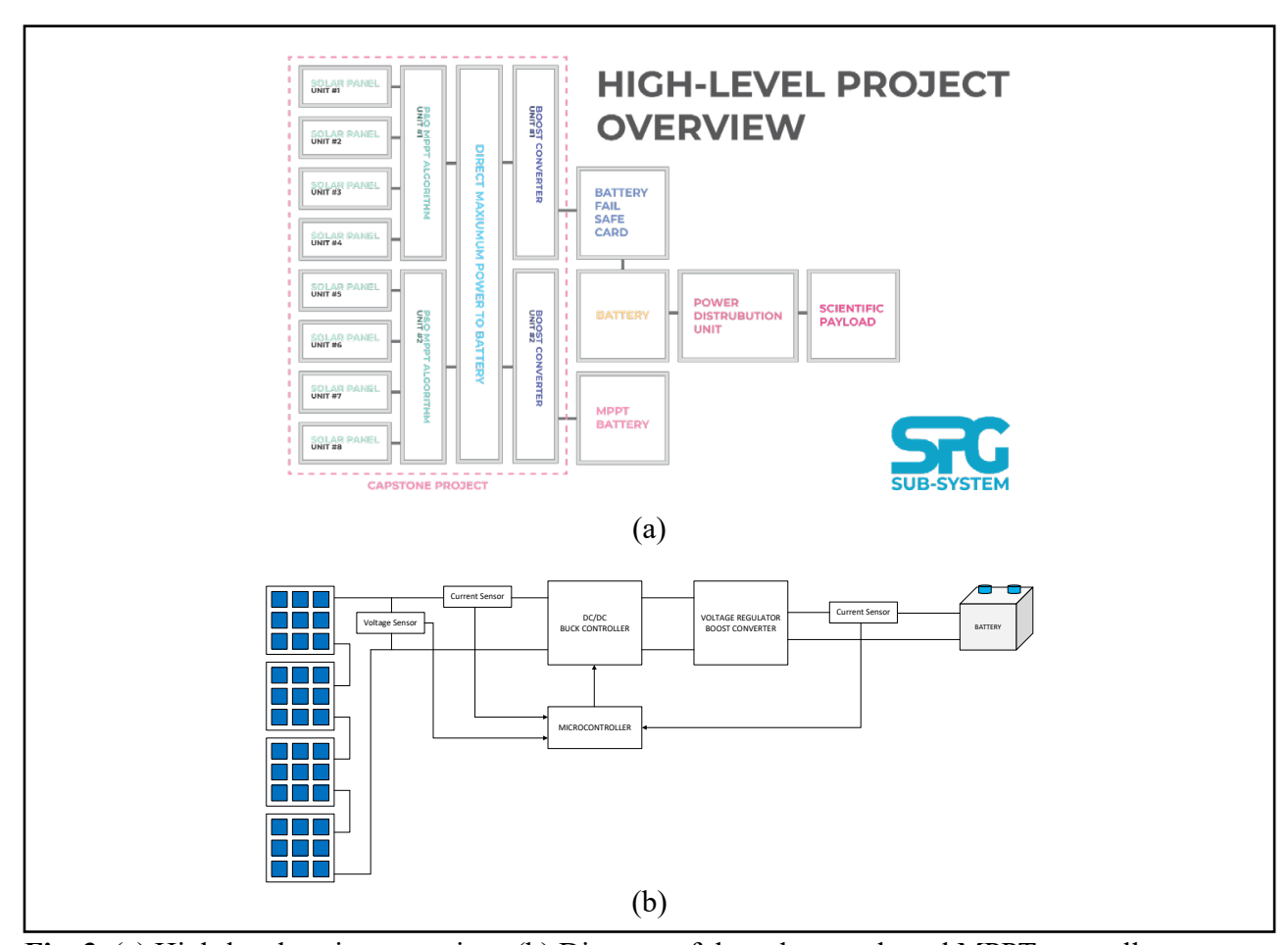

Fig. 3. (a) High-level project overview, (b) Diagram of the solar panels and MPPT controller 
Below is a list of requirements for the MPPT controller. It should be able to:

1. Charge up to four $1 \mathrm{kWh}$ Battery Units.

2. Detect if the BUs are fully charged.

3. Have the capability to power itself.

4. Take a wide range of input.

5. Accommodate up to eight solar panels.

6. Operate within the temperature range of $-400 \mathrm{C}$ to $+500 \mathrm{C}$.

\section{Design and Implementation}

This section provides a detailed description of what our team designed and implemented. It also outlines what design decisions were made and which components were selected. We also describe what challenges we encountered and how they were solved.

\subsection{Solar Panel Design}

The solar panel design consisted of five sections: selecting solar cells, developing a 3D model of the solar panel, developing a blender model of the solar panels and gondola for Collada file, STK power generation simulation, and modeling the Current-Voltage (IV) curve of the panel design.

We began the solar panel design by first selecting the solar cells. After discussions with the CSA, we decided to select the C60 SunPower solar cells. They are MonoCrystaline silicon cells with a $21 \%$ efficiency and a much larger surface area $(125 \times 125 \mathrm{~mm})$ than typical space grade solar cells used for CubeSats, such as Azurspace cells which were initially considered.

As per mission requirements, there can be up to eight solar panels placed on the gondola, thus we placed four solar panel on the front side and four others on the back side as seen in Fig. 4. This placement seemed the most logical from the structure of the gondola, but this could vary depending on which the CSA finds best for their missions.

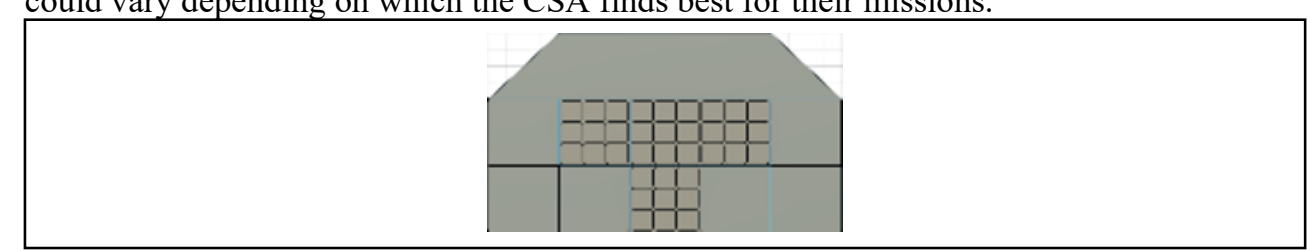

Fig. 4. Front side of simplified gondola model with four solar panels using C60 Sunpower solar Cell

\subsection{STK Solar Power Generation}

The purpose of the STK power generation model is to simulate the power generated from each solar panel during the mission. The simulation consisted of a flight from Sweden to Canada with an altitude range between $28-35 \mathrm{~km}$. To simplify the simulation, the gondola would not spin; thus, it would stay in a fixed position where four solar panels had direct sunlight, and four others had no sunlight. This was based off the mission scenario provided by the CSA.

\subsection{MPPT Schematic}

We began the design by choosing the most appropriate algorithm for the MPPT controller. As previously discussed, it was decided to use the $\mathrm{P} \& \mathrm{O}$ algorithm due to its simplicity and 
advantages in conditions where solar irradiance does not change quickly. We then moved on to deciding what would be the most efficient way to configure the MPPT controller. We decided to pursue a complete series connection for the solar panels. The problem that arose was that the solar panels will have different outputs due to having different irradiance. Solar panels with lower irradiance will have a larger impedance/resistance. The panels with higher irradiance will force higher currents to the panels with higher resistances. These shaded panels would begin to consume power instead of supplying it, reducing energy available for battery charging. In the worst case, it may cause irreversible damage to the panels. To prevent this, a "bypass diode" is typically added in parallel for each solar panel. The bypass diode will enter forward bias and provide an alternative low impedance path for the current. Arranging the solar panels in series would increase the input voltage to the MPPT controller to $24 \mathrm{~V}$.

The next part of the design is the input voltage and current measurement. This is important because these values are needed for the $\mathrm{P} \& \mathrm{O}$ algorithm. For the voltage sensor, we decide to use a simple voltage divider configuration. The Analog to Digital (ADC) converter of the dsPIC33CK Curiosity board can only take an input of 3.3V; therefore, we lowered the voltage from $24 \mathrm{~V}$ to $3.3 \mathrm{~V}$ using the voltage divider method. For the current sensor, we decided to use ACS724LMCTR-20AB-T from Allegro Microsystems. This small package is ideal for a space-constrained application.

Once we completed designing the measurement part, we began choosing the buck and boost converter. We selected the TPS5450QDDARQ1 for the buck converter as it met requirements for our application. It has a simple output method for output determination using resistors to determine its output which was required for our control approach, and provided a simple alternative to direct PWM control. This allowed us to use a variable potentiometer (MCP4017) controlled using $\mathrm{I}^{2} \mathrm{C}$ communication. Through this, we were able to manipulate the buck converter output the same way as using Pulse-width Modulation (PWM). Our design would be able to take and input voltages ranging from 6 to $25 \mathrm{~V}$. On the other hand, we decided to use the TPS40210-Q1DGQ boost converter as a regulator. This is used to provide a constant voltage of $24 \mathrm{~V}$ and $2.5 \mathrm{~A}$ to the Battery Units no matter what the input voltage of the boost converter is. The final design schematic for the buck and boost convert design is shown in Fig.5 (a) and (b).

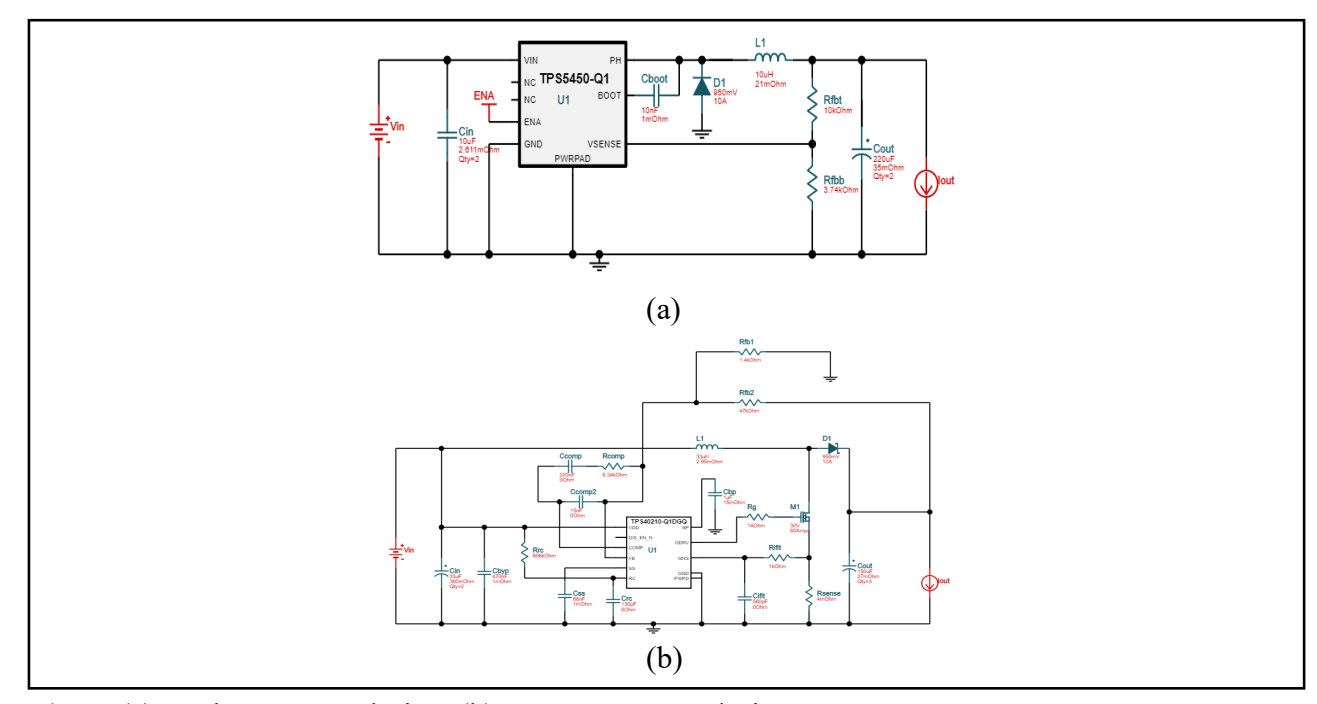

Fig. 5. (a) Buck converter design, (b) Boost converter design 
The next part of the design was to find a method to determine when to stop charging the battery and start diverting excess power to a resistive load. We added a current sensor before the BU to determine if there is still a current flow between the two. If the current reading is zero, this means that all the Battery Units are fully charged. In the end, we decided not to add a resistive load in the design and instead divert excess power to a separate MPPT BU for strictly powering the MPPT subsystem.

Once we completed the design, we determined the microcontroller output requirements. We required a microcontroller which supports $\mathrm{I}^{2} \mathrm{C}$ communication, has a built-in Analog to Digital converter (ADC), and a high number of inputs. We thus decided to use the dsPIC33CK Curiosity board to meet these requirements.

We added functionality where the four solar panels producing the most power would provide its energy to the Battery Unit and the four panels in the shade to be electrically disconnected. This is achieved by programming four optoisolators. We used LCB710 for this purpose.

\subsubsection{MPPT Flowchart}

This part demonstrates the process of how the MPPT controller should function. As seen in Fig. 6, the program starts by initializing the necessary variables. Each variable potentiometer is set to $3 \mathrm{k} \Omega$. This would give an initial voltage and current output for the solar panel. The next section is determining which combination of solar panels has a higher output voltage. It will determine which MPPT unit will charge the BUs. This is done by reading the ADC inputs. A simple math conversion can be done to convert the ADC outputs to actual current and voltage values. After determining which combination has higher power, the four opto-isolators will be configured. The next task is the P\&O algorithm. The algorithm will be applied to both MPPT units in sequence. Programming the controllers in a sequence meets the timing requirements for the MPPT. In implementing the P\&O algorithm, we added a timer. The timer is used to check if there is any minutely changes in the input voltage of the solar panels. Therefore, we do not need to apply the P\&O algorithm at every time sample. We also added a counter that will activate when a full hour has been reached. This way, we can check the two combinations of solar panels if there is any change in their output. It will also inform us if we must switch the charging the BU.

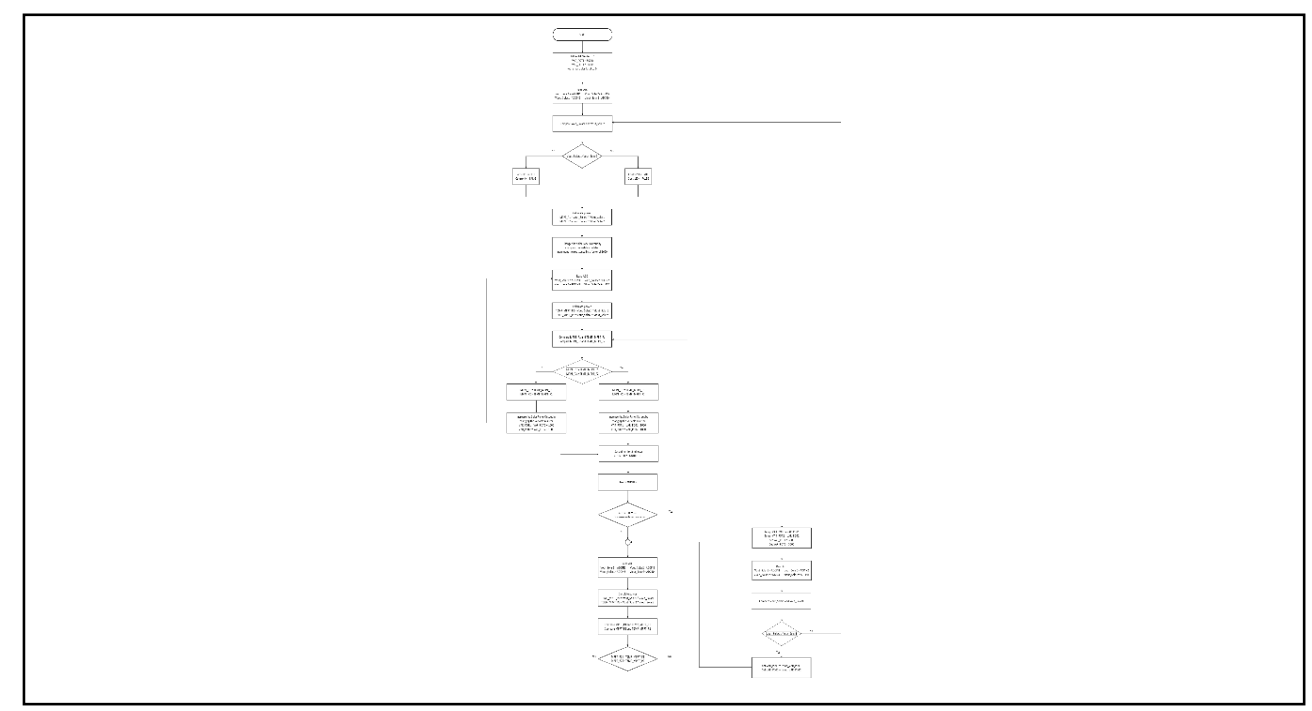

Fig. 6. MPPT Controller flowchart and P\&O algorithm 


\section{Results and Verification}

This section describes the results and verifications we achieved in our solar panel design, power generation model, and MPPT Controller.

\subsection{Solar Cell Connections}

Using the C60 SunPower solar cells, we require only 9 cells in total where they are all connected in series, greatly simplifying the solar panel design. This results in an open-circuit voltage $\left(\mathrm{V}_{\mathrm{oc}}\right)$ of $6.1 \mathrm{~V}$ and a short-circuit current $\left(\mathrm{I}_{\mathrm{sc}}\right)$ of $6.2 \mathrm{~A}$.

A second alternative for solar cells is SunPower Gen III cells which have the same surface area, and are almost identical in the electrical specification to the C60 SunPower solar cells. However, the Gen III is more durable and flexible, and could be used depending on the physical stress the solar panels may experience during missions.

Each MPPT unit can take up to four solar panels. These panels are connected in series through the MPPT controller unit and can have a $\mathrm{V}_{\text {oc }}$ of up to $24.6 \mathrm{~V}$ and an $\mathrm{I}_{\text {sh }}$ of $6.3 \mathrm{~A}$. With this connection layout, it is assumed four solar panels will be on the same side on the gondola and will experience the same solar irradiance conditions. This assumption is based off the possible mission scenario provided by the CSA. Protective diodes are added in parallel for each solar panel which prevents the panels from acting as loads during shading conditions.

Table 1. Solar Panel $\mathrm{V}_{\mathrm{oc}}$ and $\mathrm{I}_{\mathrm{sc}}$

\begin{tabular}{|c|c|c|c|c|c|c|c|c|}
\hline Solar Cell Brand & $\begin{array}{c}\text { Number of } \\
\text { cells per panel }\end{array}$ & $\begin{array}{c}\text { Cell Efficiency } \\
\text { \% }\end{array}$ & $\begin{array}{c}\text { Open Circuit } \\
\text { Voltage per cell } \\
\text { (V) }\end{array}$ & $\begin{array}{c}\text { Short Circuit } \\
\text { Current per cell } \\
\text { (A) }\end{array}$ & $\begin{array}{c}\text { Number of } \\
\text { cell in series per } \\
\text { panel }\end{array}$ & $\begin{array}{c}\text { Number of } \\
\text { cell in parallel per } \\
\text { panel }\end{array}$ & $\begin{array}{c}\text { Open Circuit } \\
\text { Voltage per panel } \\
\text { (V) }\end{array}$ & $\begin{array}{c}\text { Short Circuit } \\
\text { Current per panel } \\
\text { (A) }\end{array}$ \\
\hline SunPower C60 & 9 & 21 & 0.68 & 6.24 & 9 & 0 & 6.14 \\
\hline Azurspace 3G30A & 28 & 30 & 2.69 & 0.50 & 7 & 4 & 6.24 \\
\hline SunPower GEN III & 9 & 23 & 0.73 & 6.18 & 9 & 0 & 18.83 \\
\hline
\end{tabular}

\subsection{STK Simulation}

The mission scenario provided by the CSA indicates a possible load could be in the order of $150 \mathrm{~W}$ and could last for four days. For both solar panel designs using the AzurSpace and C60 SunPower solar cells, each solar panel has a power generation of $34 \mathrm{~W}$ at $35 \mathrm{~km}$ altitude, and $136 \mathrm{~W}$ max with four solar panels exposed to the sun, and the other four having no sunlight. At an altitude of $28 \mathrm{~km}$, the power generation per panel drops to $72 \mathrm{~W}$. The power graph with respect to time can be seen in Fig. 7 (a) and (b). In the simulations, the Azurspace $3 \mathrm{G} 30 \mathrm{~A}$ space grade solar cell efficiency was assumed to be $28 \%$, and the C60 SunPower solar cells were assumed to be $19 \%$ (both slightly lower than what is specified on their respective datasheets). 


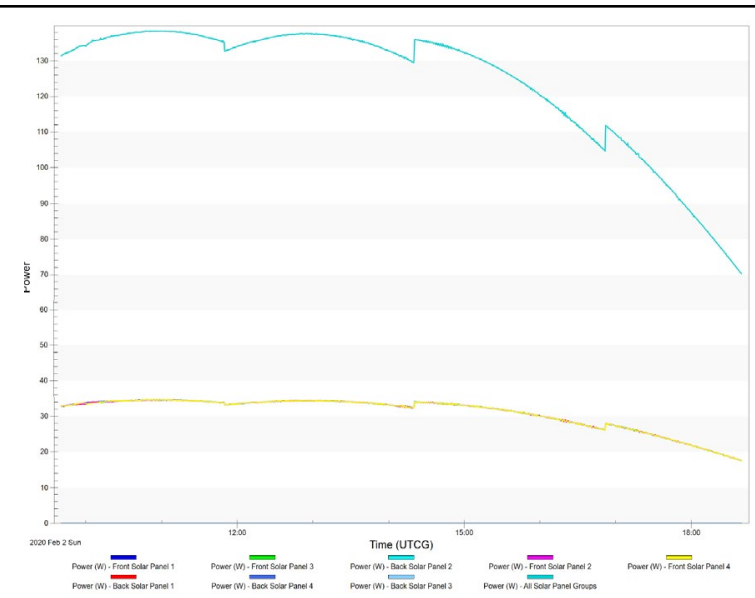

(a)

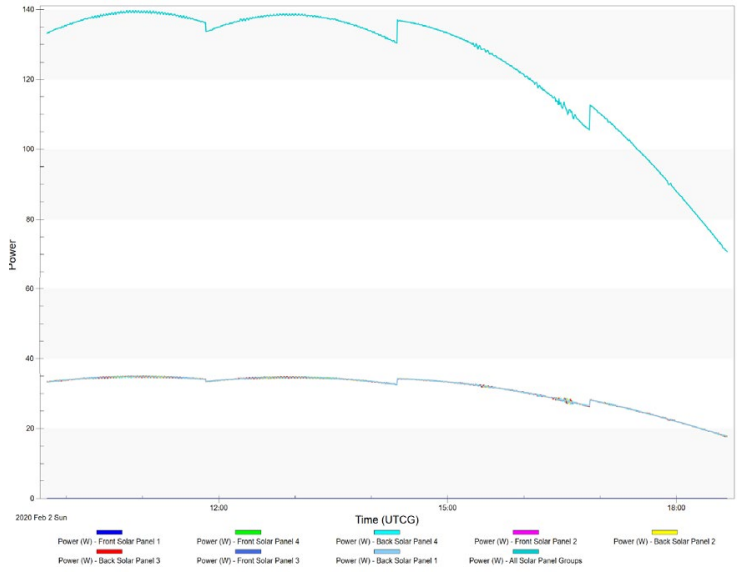

(b)

Fig. 7. Power output graph using (a) Azurspace, (b) C60 Sunpower solar cells

The power generated of $136 \mathrm{~W}$ compared to the possible actual mission load consumption of $150 \mathrm{~W}$ is close and is an acceptable initial estimate. It is important to note that system losses from the MPPT unit, batteries, failsafe board, and PDU were not considered. These losses can add up to be significant and should be taken into consideration for missions in future.

\subsection{MPPT Controller}

For this section, we will be presenting an individual simulation of the buck and boost converter. The simulation was made using the Texas Instrument WEBENCH Power Designer. Fig. 8 (a) shows that at a low current output level, the efficiency of the buck converter can go as low as $67 \%$. In addition, its efficiency decreases with increasing input voltage. At an output current of $4 \mathrm{~A}$, it can go as high as $75 \%$. Fig. 8 (b) shows that the power output of the buck converter for different voltage input is linear. On the other hand, Fig. 8(c) shows the boost converter efficiency. It is more efficient at high input voltage and can go as high as $96 \%$ efficiency. Fig. 8 (d) shows that power output is linear at the different voltage input levels. 


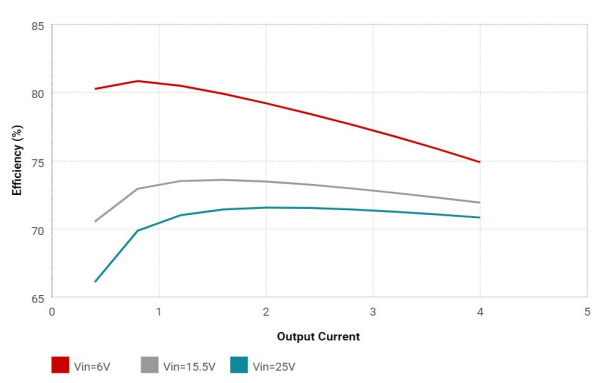

(a)

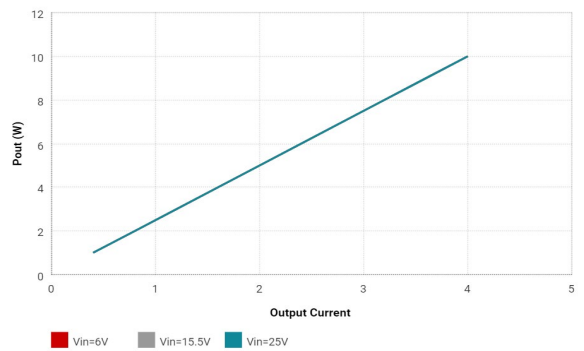

(b)

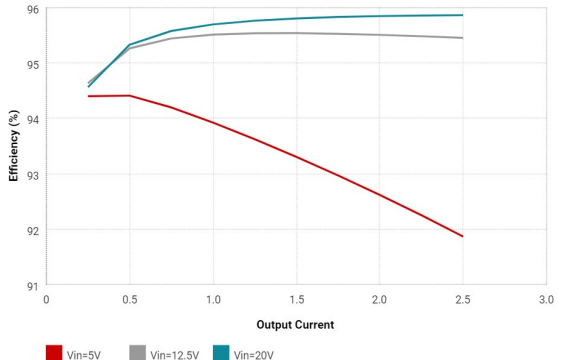

(c)

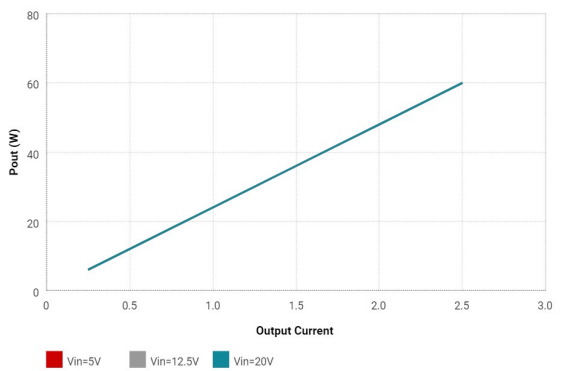

(d)

Fig. 8. (a) Buck converter efficiency for different input voltage levels, (b) Buck converter power output for different input voltage levels, (c) Boost converter efficiency for different input voltage levels, (d) Boost converter power output for different input voltage levels 


\section{Conclusions}

We successfully accomplished the following project objectives:

1.Develop a solar panel design that can generate at least $35 \mathrm{~W}$ at mission altitudes and operate within the temperature range of $-40^{\circ} \mathrm{C}$ to $+50^{\circ} \mathrm{C}$.

2. Design a centralized MPPT unit that can handle eight solar panels, integrates with CSA Battery management system (BMS), power a load of $156 \mathrm{~W}$, and operate within the temperature range of $-40^{\circ} \mathrm{C}$ to $+50^{\circ} \mathrm{C}$.

Our solar panel design specifications consist of the following:

1. Nice C60 SunPower Solar Cells

2. Open-circuit voltage of $6.14 \mathrm{~V}$

3. Short-circuit surrent of $6.24 \mathrm{~A}$

4. Efficiency of $21 \%$ (Simulation at $19 \%$ to consider power losses)

From the STK simulations, each solar panel can generate $34 \mathrm{~W}$ in direct sunlight at $35 \mathrm{~km}$ altitude above sea level. This drops to $18 \mathrm{~W}$ at $28 \mathrm{~km}$ altitude above sea level. During the STRATOS missions, if four solar panels are exposed to sunlight, and the other four are shaded, the power generation will result to $136 \mathrm{~W}$, without considering system power losses. In a mission that does not require a positive power budget, a load of over $136 \mathrm{~W}$ is feasible to implement. To guarantee scientific payload stays on for the mission duration, it is important to do the calculation between power consumption and generation and determine how long till the battery capacity reaches its minimum threshold and shuts down all connected equipment.

We were successfully able to develop a MPPT controller unit that meets the requirements requested by the CSA. The designed MPPT controller is able to meet six of the seven requirements. It accommodates up to eight solar panel inputs. It has its own power source that can be charged using the MPPT controller itself. The voltage input for the controller has a range of $6 \mathrm{~V}$ to $25 \mathrm{~V}$. Lastly, the controller can provide a voltage and current output of 24 $\mathrm{V}$ and $2.5 \mathrm{~A}$.

\section{Recommendation for Future Work}

In this section, we describe recommendations for future possible work to improve and build on this project.

\subsection{Solar Panel Testing}

The solar panels should be assembled and tested with the C60 Sunpower solar cells. The tests should be a combination of physical stress and temperature range that will be experienced during the STRATOS missions. It is also essential to test the efficiency change the solar panels will experience with temperature changes.

The maximum output voltage and current and the MPPT point for different conditions should also be tested to confirm compatibility with the MPPT unit.

\subsection{Power Generation Model}

In our STK simulation, we considered a fixed position of the gondola, where half the solar panels were always in sunlight and the other half in the shade. This was based on the given theoretical assumptions from the CSA, which might be different in practice. The simulations should be done with different orientations of the gondola, where solar panels on the side could experience different solar irradiance conditions. 
Our simulation also did not include the full mission time-lapse of four days in which the gondola could experience nightfall. In this case, solar panels will generate no energy. Thus, this needs to be considered in a complete power model, which includes both power generation and consumption at different stages of the mission.

Power losses from the MPPT unit, BUs, and PDU should also be measured to build a complete power generation and consumption model.

\subsection{Electromagnetic Interference (EMI) Research}

The testing of electromagnetic interference caused by the MPPT unit should be done. It is crucial because if the MPPT controller has electromagnetic emissions, it may need to be a certain distance away from other instruments on the gondola (similar to the BUs).

\subsection{Powering the MPPT Unit}

The MPPT unit currently requires its own rechargeable battery and BMS. Further research is required to select a battery of appropriate size that meets the requirements of the CSA STRATOS missions. A small-size BMS for the battery also needs to be developed for the MPPT unit.

An alternative approach is to adjust the MPPT unit design to where it is only turned on when there is power from the solar panels and turned off when there is no power. This process must be automated.

\subsection{Buck Converter}

In our design, we use an off-the-shelf buck converter that is not directly controlled by PWM but through a digital variable resistor. We were not able to test this approach for an MPPT, and it should be tested to confirm its efficiency. Another approach is to design a buck converter specifically for this application.

\subsection{Thermal Simulations of the MPPT Controller}

Due to time constraints and challenges using Piecewise Linear Electrical Circuit Simulation (PLECS), we could not run thermal simulations for the MPPT controller. This is a recommended task as it is important to know the thermal profile of the electronics, and determine how they will behave in the Aluminum enclosures during mission flights.

\subsection{Diverting excess power to a resistive load}

In [10], it mentions "during ground testing, the PDU can accept power from an external lab power supply. This supply can work in conjunction with the batteries because it is protected by two diodes, preventing current from the batteries returning to it." We believe it would be useful to try and take advantage of this feature and divert excess power straight to the PDU instead of dissipating it in a resistive load. This may require modification to the PDU schematic. However, it would be worth the effort as dissipating excess power in space missions such as the STRATOS missions may not be the most efficient way of handling excess power. The missions may contain periods of nightfall, and the batteries need to be as close to the maximum capacity as possible. 


\subsection{Powering the MPPT Unit from the BUs}

Instead of the MPPT unit containing its rechargeable battery and BMS, it would be of benefit if the MPPT was powered straight from the BUs. This would mitigate the complexity and the number of components used in the system.

\subsection{Positive Power Budget}

Based on discussions with the CSA, the current goal is not to have a power system that has a positive power budget. The missions could range from four to six days, and it is expected that the BUs plus the power generation from the MPPT last for that the mission duration. If an instrument consumes more power than expected, and the battery capacity runs out, instruments would turn off, and it would result in a mission failure. For a complete power system, a positive power budget is always best as it guarantees that all scientific instruments stay on for the mission duration.

\section{Acknowledgement}

We would like to express our gratitude to the Canadian Space Agency for providing us with this challenging project. We want to thank Martin Laflamme and Vlad Popovici, engineers in the CSA STRATOS Team for all their support on this project. Thank you for being patient with us and for your timely support and guidance throughout.

We would also like to thank our friends and family for their encouragement and support. 


\section{References}

1. C. S. Agency, "About STRATOS, the CSA's stratospheric balloon program," Jul. 2018. [Online]. Available: https://www.asc-csa.gc.ca/eng/sciences/balloons/stratos.asp. [Accessed: 30 Sep. 2019]

2. F. Dinçer and M. E. Meral, "Critical factors that affecting efficiency of Solar," Smart Grid and Renewable Energy, pp. 47-50, (2016)

3. Images SI, Inc., "Photovoltaic cells - generating electricity," [Online]. Available: https://www.imagesco.com/articles/photovoltaic/photovoltaic-pg4.html [Accessed: 30 Sept. 2019]

4. S. Haffner, L. Pereira, L. Pereira, and L. Barreto, "Multistage model for distribution expansion planning with distributed generation-part I: problem formulation," IEEE Transactions on Power Delivery, 23 (2), pp. 915-923, (2008)

5. M. C. LoPresto and A. D. A. Jacobs, "An exercise in modelling using the US Standard Atmosphere," Physics Education, pp. 76-80, (2006)

6. S. E. Babaa, M. Armstrong, and V. Pickert, "Overview of maximum power point tracking control methods for PV systems," Journal of Power and Energy Engineering, pp. 59-72, (2014)

7. S. Daraban, D. Petreus, C. Morel, and M. Machmoum, "A novel global MPPT algorithm for distributed MPPT," Proceedings of the $15^{\text {th }}$ European Conference on Power Electronics and Applications (EPE), pp. 1-6, (2013)

8. J. Gosumbonggot and G. Fujita, "Global maximum power point tracking under shading condition and hotspot detection algorithms for photovoltaic systems," Energies, (2019)

9. S. G. A. Pradeep and Kumar Yadav, "Comparison of MPPT algorithms for DC-DC converters based PV systems," International Journal of Advanced Research in Electrical, Electronics and Instrumentation Engineering, 1 (2012)

10. Canadian Space Agency, "CSA-STRATOS-DP-0055," Safety Data Package, (2019) 


\section{Appendix}

This section contains the appendices of the paper.

\subsection{Appendix A - MPPT Printed Circuit Board (PCB) and MPPT Enclosure}

To incorporate the above-illustrated objectives and design specifications, a PCB is developed to implement our design as seen in Fig. 9 (a). The PCB contains a $0.25 \mathrm{~mm}$ track width with a $0.2 \mathrm{~mm}$ track clearance. The PCB design included a $3.81 \mathrm{~mm}$ diameter holes which will be used in conjunction with a $3 \mathrm{~mm}$ screws. Furthermore, there are two $25 \times 2$ and a $2 \times 2$ throughhole connector pins integrated into the PCB to be used as a hat for the Microchip dsPIC33ck curiosity development board. The connectors used were $2.54 \mathrm{~mm}$ PCB headers for a seamless connection with the curiosity board. There are also $131 \times 22.54 \mathrm{~mm}$ PCB headers to connect solar panels and battery connector ports. For simple implementation of our PCB design, all passive components are surface-mount device (SMD) standards parts for ease of production. All resistors used in the PCB design were R 2512 resistor footprints, capacitors were C 2220 capacitor footprints and inductors were $12 \mathrm{~mm}$ x $12 \mathrm{~mm}$ x H8 mm inductor footprints. To ensure the safekeeping and continued operation of our PCB design, we deployed an enclosure for protection against large impacts, weather erosion, and liquid. To guarantee the enclosure will be waterproof, gaskets are proposed for usage to maintain a sealed housing. Furthermore, to ensure the enclosure will withstand large variation of impacts, the proposed material for this design was aluminum which is like the enclosures used by the CSA for the PDUs. Our proposed enclosure is shown in Fig. 9 (b).

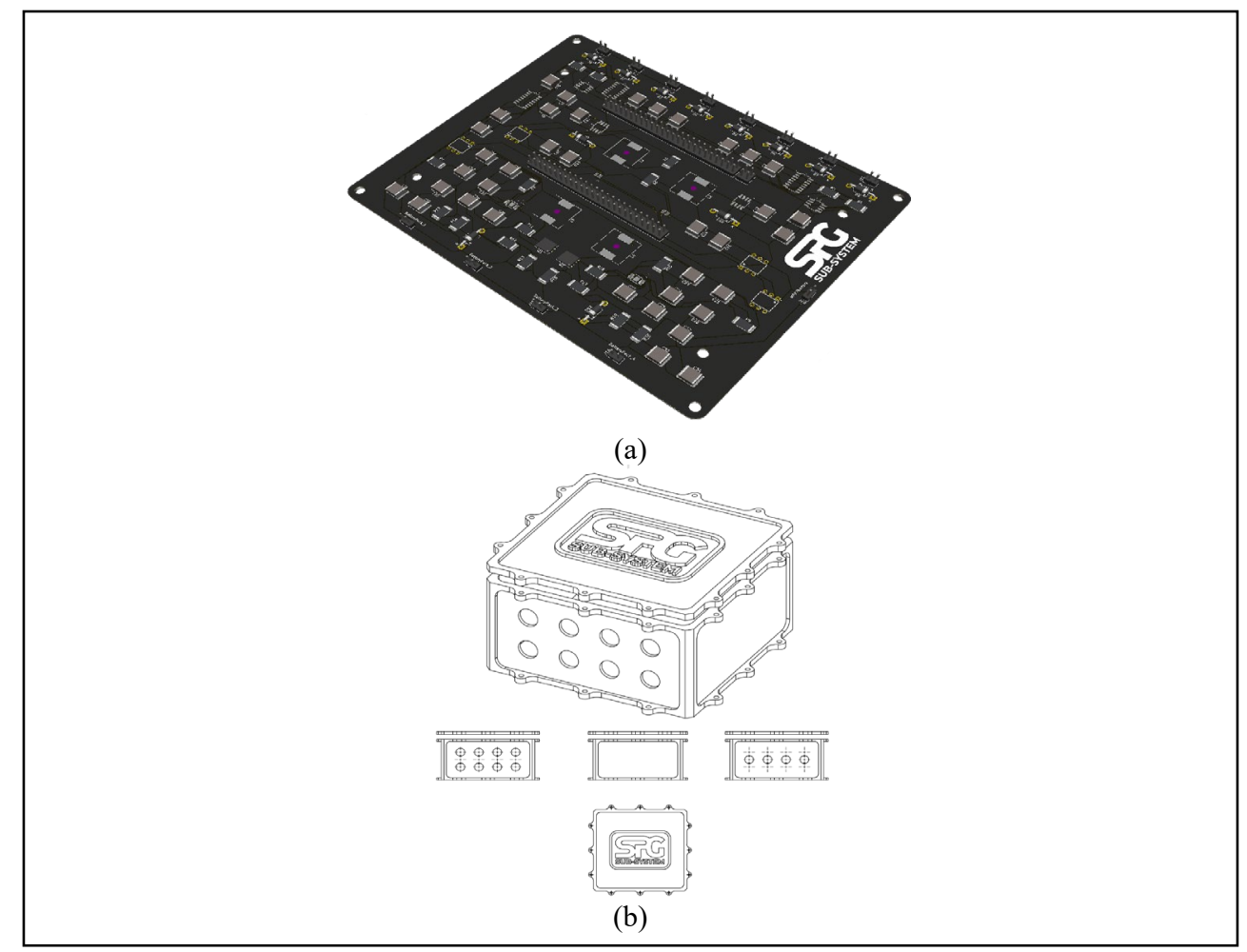

Fig. 9. (a) Centralized MPPT unit's PCB, (b) Enclosure outline sheet 